Andrea Lukács, Emőke Kiss-Tóth, Beatrix Varga, Andrea Soós, Peter Takác and László Barkai (2013). BENEFITS OF CONTINUOUS SUBCUTANEOUS INSULIN INFUSION ON QUALITY OF LIFE. International Journal of Technology Assessment in Health Care, 29, pp 48-52. doi:10.1017/S0266462312000797.

\title{
Benefits of continuous subcutaneous insulin infusion on quality of life
} Andrea Lukács ${ }^{1}$, Emőke Kiss-Tóth ${ }^{1}$, Beatrix Varga ${ }^{2}$, Andrea Soós ${ }^{3}$, Peter Takác ${ }^{1}$, László Barkai $^{1,3,4}$

${ }^{1}$ Faculty of Health Care, University of Miskolc, Miskolc, Hungary

${ }^{2}$ Faculty of Economics, University of Miskolc, Miskolc, Hungary

${ }^{3}$ Department of Pediatrics, Borsod County University Hospital, Miskolc, Hungary

${ }^{4}$ Miskolc, Hungary, Postgraduate Institute of Pediatrics, Medical and Health Science Center, University of Debrecen, Debrecen, Hungary

Purpose: The aim of this study was to compare the general health-related quality of life (HRQoL), the metabolic control $\left(\mathrm{HbA}_{1 \mathrm{c}}\right)$, the anthropometric measurement, and the cardiorespiratory fitness (expressed by $\mathrm{VO}_{2 \max }$ ) in youths with type 1 diabetes treated with continuous subcutaneous insulin infusion (CSII) to those receiving multiple daily injections (MDI). We looked for factors influencing the HRQoL and metabolic control.

Methods: A total of 239 patients treated with CSII (51 girls and 53 boys) or MDI (64 girls and 71 boys) between ages 8 and 18 years were assessed with the Pediatric Quality of Life Inventory, Generic Core Scales, and Diabetes Module. VO2max was evaluated using the 20meter shuttle run test.

Results: CSII group had significantly better HRQoL according to both child self-report and parent proxy-report. Youths with CSII reported better physical, emotional, and school-related functioning, and had less diabetes-related fear and symptoms than the MDI group. There were no significant differences in body mass index z-scores, insulin doses, $\mathrm{HbA}_{1 \mathrm{c}}$, and $\mathrm{VO}_{2 \max }$ between the groups. HRQoL was predicted by the CSII therapy $(\beta=-0.220 ; p<.001)$ and the $\mathrm{VO}_{2 \max }(\beta=0.386 ; \mathrm{p}<.001)$, other clinical and anthropometric parameters had no effect; the HbA1c was predicted only by VO2max $(\beta=-0.353 ; \mathrm{p}<.001)$.

Conclusions: Diabetic youths treated with CSII therapy have better HRQoL than those treated with MDI. There are no differences between the investigated groups in anthropometric data, glycated hemoglobin, and physical fitness. Moreover, good physical fitness has an important role in achieving better metabolic control and HRQoL, which underlines the importance of regular aerobic exercise in the treatment and care of type 1 diabetes in childhood.

Keywords: Type 1 diabetes mellitus, Children, Adolescents, Health-related quality of life, Continuous subcutaneous insulin infusion 
Type 1 diabetes mellitus (T1DM) is a life-long disease, the incidence of which is increasing worldwide among children and adolescents (1). Multiple daily injection (MDI) treatment is the most widely used method of insulin administration. This regimen involves intermediate or long acting insulin once or twice a day as basal dose and rapid acting insulin at each meal time, and patients need to administer at least three or more injections a day (2). A technological alternative to this method of insulin delivery is the continuous subcutaneous insulin infusion (CSII or insulin pump therapy), which was developed in the 1970s (3), but gained popularity among diabetic patients in the 1990swhen theDiabetesControl and ComplicationTrial showed the benefits of intensive insulin therapy for achieving tight metabolic control and reducing the risk of micro- and macrovascular complications

(4). Insulin pump therapy is a commonly used alternative to MDI in the treatment of pediatric T1DM. The portable insulin pump is a mechanical medical device that offers the most physiological way of insulin delivery because it simulates the normal pattern of insulin secretion. The insulin pump gives flexibility to the patients in many areas of life (5). The insulin pump therapy can be used even for a very young age-group (6). Although the

number of patients treated with CSII is growing rapidly, there is an issue about the clear advantages of insulin pump therapy over MDI in childhood (7-10). The strength of evidence of the utilization data in the recent randomized controlled trials and meta-analyses was low or insufficient comparing CSII with MDI for health-related quality of life (HRQoL), metabolic control, and anthropometric measurement. There have been only a few studies included assessing children and adolescents, and all trials suffered from limited sample sizes. Research into the use of CSII in children and adolescents is needed.

Regular exercise plays an important role in the treatment protocol for diabetes mellitus. Especially good cardiorespiratory fitness is essential for patients with T1DM as the diabetes is associated with a substantially increased risk of developing cardiovascular disease (11). It has several health-related benefits; advantages include psychological well-being, normalization in blood lipid profile, lower blood pressure, and reduced exogenous insulin requirements $(12 ; 13)$. Studies found that youths with T1DM have lower cardiorespiratory fitness compared with healthy peers $(14 ; 15)$, but we did not find studies that compared the cardiorespiratory fitness of youths with T1DM treated with CSII to MDI therapy.

The present study was designed to compare the HRQoL, the metabolic control, the anthropometric measurement and the cardiorespiratory fitness in youths withT1DM treated with CSII to MDI therapies. It also aimed to assess the factors influencing the HRQoL and metabolic control in patients with T1DM.

\section{PATIENTS AND METHODS}

\section{Patients and Settings}

The study participants were recruited from diabetes-based summer camps and were eligible for this study if they were diagnosed with T1DM for at least 2 years, were 8-18 years old, treated with CSII or MDI. Exclusion criteria were physical problems that made it difficult for the patient to carry out the shuttle run test. There were 239 patients with T1DM treated with CSII (51 girls and 53 boys) or MDI (64 girls and 71 boys) who took part in this crosssectional survey. The camps were supported by foundations so the participation was made possible for everyone regardless of the financial background of the families. All the patients from 8 to 18 years old were invited to take part in the study, but there were fourteen children who did not meet the requirements for the 20-meter shuttle run test due to musculo-skeletal, cardiac or respiratory disorders; and there were fifteen parents who did not complete the questionnaire. Participants were white/non-Hispanic. The investigated groups did not differ significantly in gender, age and in insulin dose. Table 1 presents the sample characteristics. 
The youths and their parents were informed about the purpose and methods of the research verbally and in written form. Written consent was obtained from the parents and verbal assent from youths under age 18 before the completion of study measurement. This research study was approved by the Borsod-Abaúj-Zemplén County Regional Scientific and Research Ethics Committee.

\section{Measurements}

Health-Related Quality of Life Measurement. HRQoL was assessed with the Pediatric Quality of Life Inventory (PedsQL) 4.0 Generic Core Scale (GCS). The PedsQL is a measurement model for HRQoL of healthy and chronically ill and youths with acute illnesses. The scale contains developmentally appropriate child self-report (5-18 years) and parent proxy-report (2-18 years) versions. The twenty-three-item GCS encompasses four subscales: physical functioning (eight items), emotional functioning (five items), social functioning (five items), and school functioning (five items) (16). The participants rated how much of a problem they have had in the previous month on a five-point Likert-type response scale. The answer was 0 if there were no problems with the above-mentioned functions and 4 if it was almost always a problem. Items were reverse-scored and linearly transformed to a $0-100$ scale, where $0=100$, $1=75,2=50,3=25$, and $4=0$. Scores were computed as the sum of the items divided by the number of items answered.

The multidimensional PedsQL DiabetesModule (DM) was developed to measure diseasespecific HRQoL for T1DM (17). The DM has five subscales: diabetes symptoms (eleven items), treatment barriers (four items), treatment adherence (seven items), worry (three items), and communication (three items (17).

Normal range of total and subscale scores of GCS and DM are not available in the literature. Higher scores indicate better quality of life. In this study, the total scores and subscale scores of the GCS and subscale scores of DMwere used for comparing HRQoL of the CSII and MDI groups.

Cardiorespiratory Fitness. Cardiorespiratory fitness was measured using the 20-meter shuttle run test. This test was originally developed by Léger and Lambert. The participants had to run between two lines, 20 meters apart, at the sound of a prerecorded CD signal. The initial speed was $8.5 \mathrm{~km} /$ hour and it progressively increased by $0.5 \mathrm{~km} /$ hour every minute until the runner could no longer keep up with the required speed. The maximal oxygen consumption was predicted from the speed of the last stage the participants completed using the regression equation of Léger et al. (18). The validity of the 20 -m shuttle run test to predict $\mathrm{VO}_{2 \max }$ has been previously established (19). $\mathrm{VO}_{2 \max }$ is the best measure of cardiorespiratory fitness. It varies greatly between individuals. The normative data for $\mathrm{VO}_{2 \max }(\mathrm{ml} / \mathrm{kg} / \mathrm{min})$ in 10 - to 19 year-old males, who are not athletes, are 47-56, and 36-46 in females (20). If blood glucose measured before the test was out of the target range $(5-10 \mathrm{mmol} / \mathrm{L})$, a new appointment was given to perform the test on another day.

Body Mass Index and Metabolic Control. Height and weight were measured for calculating BMI (kg/m2) and BMI z-score (adjusted forchild age and sex). Z-scores (or standard deviation scores) was calculated according to the formula (Xi-Mx)/SD, where $\mathrm{Xi}$ is the actual measurement, $\mathrm{Mx}$ is the mean value for that age and sex, and SD is the standard deviation corresponding to that age and sex. In accordance with the guidelines of the Hungarian

National Institute of Child Health, a z-score between the 3rd and 90th percentile was considered normal (21). The hemoglobin $\mathrm{A}_{1 \mathrm{c}}\left(\mathrm{HbA}_{1 \mathrm{c}}\right)$ values for the metabolic control were extracted from the medical records of the study participants. 


\section{Statistical Analysis}

We used SPSS 19.0 statistical software for data analysis. Descriptive statistics were presented as mean and \pm standard deviation. All reported results were two-tailed; significance level was set at $p$ values $\leq .05$. To compare the results of patients treated with CSII and MDI we used an independent t-test. Gender difference was evaluated with the Pearson Chi-square test. Stepwise multiple regression analysis was carried out to establish the factors that influenced the generic HRQoL and the metabolic control $\left(\mathrm{HbA}_{1 \mathrm{c}}\right)$.

\section{RESULTS}

\section{Health-Related Quality of Life}

We observed significant differences in HRQoL between the CSII and MDI groups regarding both the child self-report (CSR) $(p<.001)$ and the parent-proxy report (PPR) $(p<.001)$ according to the GCS total scores. Youth with CSII therapy had higher scores. The difference was caused by the divergent emotional functioning (CSR: $\mathrm{p}<.001$; PPR: $\mathrm{p}<.001$ ) and better physical functioning (CSR: $p=.008$; PPR: $p=.005$ ) between the two groups. The youths treated with CSII reported significantly better school functioning than those with MDI therapy (CSR: $\mathrm{p}=.004)$. Regarding the diabetes-specific subscales, we found that CSII patients had significantly a higher subscale score in Diabetes symptoms (CSR: $\mathrm{p}=.001$; PPR: $\mathrm{p}=.001$ ) and in Worry subscale (CSR: $\mathrm{p}<.001$; PPR: $\mathrm{p}<.001)$. The GCS total score and subscale scores and DM subscale scores are presented in Table 2.

\section{Cardiorespiratory Fitness, Metabolic Control, and Anthropometric Measurement}

We computed themaximal oxygen consumption $\left(\mathrm{VO}_{2 \max }\right)$ separately by gender using the 20meter shuttle run test.We found no significant differences between the CSII and MDI groups either in boys or girls. The metabolic control between the CSII and MDI groups, as well as the BMI z-scores, was similar without any notable differences (Table 1).

\section{Predictors of General Health-Related Quality of Life and Metabolic Control}

Using stepwise multiple regression analysis, we found that two factors, the $\mathrm{VO}_{2 \max }$ value and the method of intensive therapy proved to be significant independent predictors of the general HRQoL. Age, gender, diabetes duration, $\mathrm{HbA}_{1 \mathrm{c}}$, insulin dosage, and BMI z-scoreswere not significant in the model. The results of the regression indicated that $\mathrm{VO}_{2 \max }$ and the method of therapy explained 21.4 percent of the variance (Table 3). When $\mathrm{HbA}_{1 \mathrm{c}}$ was used as a dependent variable in the multiple regression model, only the maximal oxygen consumption proved to be the single significant predictor of metabolic control $(\mathrm{B}=-0.093, \mathrm{SE}(\mathrm{B})=0.016$, $\beta=-0.353, \mathrm{t}=-5.813 ; \mathrm{p}<.001 ; \mathrm{R}=0.353 ; \mathrm{R} 2=0.125$ ).

\section{DISCUSSION}

The main strength of our study is that we evaluated two modalities of intensive insulin therapy from clinical, anthropometric, HRQoL, and physical fitness points of view using the same cohort and a great sample size. The investigated groups were comparable, and represented patients from different parts of Hungary. There are a few limitations in this study. The findings of this cross-sectional nonrandomized cohort study design may have been caused by selection bias to the treatment groups, not the treatment modality, although the whole childhood population, who participated in the summer camps and met the inclusion criteria, was addressed to take part in the study. Costeffectiveness data to determine superiority between the two interventions and the socioeconomic status of the families were not available. The insulin pump is almost fully supported by the National Health Insurance in Hungary, so the use of an insulin pump device does not depend on the family's financial 
situation in Hungary. Our groups represented one ethnicity. These imperfections may limit the generalizability of the findings.

In this study, we compared the HRQoL, the metabolic control, theBMIz-score, and the cardiorespiratory fitness expressed by $\mathrm{VO}_{2 \max }$ in youths with T1DM treated with CSII to MDI therapy with age range of 8-18 years. Patients treated with insulin pump therapy had better HRQoL than those treated with MDI. This result was confirmed by the parents' answers. Recently, SEARCH for Diabetes in Youth Study from the United States had similar results using the PedsQL GCS (22). Both the child self-report and the parent proxy-report indicated significantly more stable emotional and physical functioning due to flexibility of the use of an insulin pump.Youths with CSII therapy reported better school achievement, although this was not confirmed by the parents' answers. The CSII group had less annoying signs of diabetesrelated symptoms that might affect their everyday quality of life. An important finding of our study is that youths with CSII therapy and their caregivers worry less about the efficiency of the medical treatment, the long-term complications and hypoglycemic episodes. This finding is supported by survey of Bode et al. (23).

Results from previous studies are controversial regarding the relationship between metabolic control and HRQoL. In this study, there were no significant differences in $\mathrm{HbA}_{1 \mathrm{c}}$ between the two investigated groups, suggesting that the method of the intensive therapy had no effect on metabolic control. Our finding with greater sample size agrees with Pánkovska's systematic review and meta-analysis, namely that there is no important difference in glycemic control in patients treated with insulin pumps compared with MDI (24). We had no comparison data from the literature regarding the maximal oxygen consumption between the CSII and MDI groups. Studies examining the physical fitness in patients with T1DM did not distinguish between the methods of intensive insulin therapy. Our result is unique in this field; the method of the intensive insulin therapy has no significant effect on the young patients' cardiorespiratory fitness (expressed by $\mathrm{VO}_{2 \max }$ ). Analyzing the total patients with T1DM in the regression model, we found two predictors that explained the better HRQoL. From these results, we would conclude that the CSII therapy and the better maximal oxygen consumption are related to better HRQoL perception in pediatric diabetic patients. The favorable metabolic control was explained only by the higher $\mathrm{VO}_{2 \max }$ value. These results underline the importance of the cardiorespiratory fitness both in achieving better HRQoL and more favorable metabolic control. Although CSII therapy had no effect on the metabolic control and cardiorespiratory fitness, this type of treatment influenced the HRQoL positively, which is a remarkable finding. This could be due to greater emotional balance and less fear of diabetes-related symptoms. Parental anxiety is known in the literature (25). We also found that parents ofMDI group had more diabetes-related worry and stress associated with their child's medical care than parents of children using CSII. The long-term parental fear may be correlated with overprotection and may limit the diabetic child's self-esteem and build panic issues in children as well (26). The main goal in diabetes management is to achieve good metabolic control and improve quality of life of the young patients. CSII therapy seems to be a more effective way to make the young patient feel better, mainly by giving psychological stability and reducing the burden of diabetes-related anxiety.

In conclusion, children and adolescents with T1DM treated with CSII therapy have better HRQoL than those treated with MDI of insulin. There are no differences between the investigated groups in anthropometric data, glycated hemoglobin, and physical fitness. Moreover, good physical fitness has an important role in achieving bettermetabolic control andHRQoL which underlines the importance of the regular aerobic exercise in the treatment and care of T1DM in childhood. 


\section{CONFLICTS OF INTEREST}

Andrea Lukács has received a Hungarian Diabetes Association grant and László Barkai reports a grant to his institution by the European Union, co-financed by the European Social Fund. The other authors report no potential conflicts of interest.

\section{REFERENCES}

1. Soltesz G, Patterson CC, Dahlquist G; (EURODIAB Study Group). Worldwide childhood type 1 diabetes incidence - what can we learn from epidemiology? Pediatr Diabetes. 2007;8(Suppl 6):6-14.

2. Bangstad H-J, Danne T, Deeb LC, et al. Insulin treatment in children and adolescentswith diabetes (ISPADClinical Practice Consensus Guidelines 2009 Compendium). Pediatr Diabetes. 2009;10(Suppl 12):82-99.

3. Tamborlane WV, Sherwin RS, Genel M, Felig P. Reduction to normal of plasma glucose in juvenile diabetes by subcutaneous administration ofinsulin with a portable infusion pump. $\mathrm{N}$ Engl J Med. 1979;300:573-8.

4. Diabetes Control and Complications Trial Research Group. Effect of intensive diabetes treatment on the development and progression of longterm complications in adolescents with insulin-dependent diabetes mellitus. J Pediatr. 1994;125:177-88.

5. Phillip M, Battelino T, Rodriguez H, Danne T, Kaufman F. Use of insulin pump therapy in the pediatric age-group: consensus statement from the European Society for Paediatric Endocrinology, LawsonWilkins Pediatric Endocrine Society, International Society for Pediatric and Adolescent Diabetes, endorsed by the American Diabetes Association and the European Association for the Study of Diabetes. Diabetes Care. 2007;30:1653-62.

6. Wilson DM, Buckingham BA, Kunselman EL, et al. A two-center randomized controlled feasibility trial of insulin pump therapy in young children with diabetes. Diabetes Care. 2005;28:15-9.

7. Monami M, Lamanna C, Marchionni N, Mannucci E. Continuous subcutaneous insulin infusion versus multiple daily insulin injections in type 1 diabetes: a meta-analysis. Acta Diabetol. 2010;47(Suppl 1):77-81.

8. Misso ML, Egberts KJ, Page M, O’Connor D, Shaw J. Continuous subcutaneous insulin infusion (CSII) versus multiple insulin injections for type 1 diabetes mellitus.

Cochrane Database Syst Rev. 2010;1:CD005103.

9. Cummins E, Royle P, Snaith A, et al. Clinical effectiveness and costeffectiveness of continuous subcutaneous insulin infusion for diabetes: systematic review and economic evaluation. Health Technol Assess. 2010;14:iii-iv, xi-xvi, 1-181.

10. Golden SH, Brown T, Yeh HC, et al. Methods for insulin delivery and glucose monitoring: comparative effectiveness. Comparative Effectiveness Review No. 57. (Prepared by Johns Hopkins University Evidence-based Practice Center under Contract No 290-200710061-I.) AHRQ Publication No. 12-EHC036-EF, Rockville, MD: Agency for Healthcare Research and Quality. [cited 2012 July]. Available from: www.effetivehealthcare.ahrq.gov/reports/final.cfm.

11. American Diabetes Association. Physical activity/exercise and diabetes mellitus. Diabetes Care. 2004;27(Suppl 1):S58-62.

12. Peirce NS. Diabetes and exercise. Br J Sports Med. 1999;33:161-73.

13. RiglaM, S'anchez-Quesada JL, Ord'o nez-Llanos J, et al. Effect of physical exercise on lipoprotein(a) and low-density lipoprotein modifications in type 1 and type 2 diabetic patients. Metabolism. 2000;49:640-7.

14. Komatsu WR, Gabbay MA, Castro ML, et al. Aerobic exercise capacity in normal adolescents and those with type 1 diabetes mellitus. Pediatr Diabetes. 2005;6:145-9. 
15. Williams BK, Guelfi KJ, Jones TW, Davis EA. Lower cardiorespiratory fitness in children with type 1 diabetes. Diabet Med. 2011;28:1005-7.

16. Varni JW, Seid M, Kurtin PS. PedsQL 4.0: reliability and validity of the pediatric quality of life inventory version 4.0 generic core scales in healthy and patient populations. Med Care. 2001;39:800-12.

17. Varni JW, Burwinkle MA, Jacobs JR, et al. The PedsQLTM in type 1 and type 2 diabetes: reliability and validity of the Pediatric Quality of Life InventoryTM Generic Core Scales and type 1 Diabetes Module. Diabetes Care. 2003;26:631-637.

18. Léger LA, Mercier D, Gadoury C, Lambert J. The multistage 20 metre shuttle run test for aerobic fitness. J Sports Sci. 1988;6:93-101.

19. Liu NY, Plowman SA, Looney MA. The reliability and validity of the 20-meter shuttle test in American students 12 to 15 years old. Res Q Exerc Sport. 1992;63:360-5.

20. Kenney L, Wilmore JH, Costill DL. Physiology of Sport and Exercise. 5th ed.

Champaign, IL: Human Kinetics; 2005:269.

21. Hungarian National Institute of Child Health. [cited 2012 April 18]. Available from: http://www.ogyei.hu/upload/files/gyermekkori Taplaltsag.pdf.

22. Naughton MJ, RuggieroMS, Lawrence JM, et al. (SEARCH for Diabetes in Youth Study). Health-related quality of life of children and adolescents with type 1 or type 2 diabetes mellitus. Arch Pediatr Adolesc Med. 2008;162:649-57.

23. Bode BW, Tamborlane WV, Davidson PC. Insulin pump therapy in the 21st century. Strategies for successful use in adults, adolescents, and children with diabetes. Postgrad Med. 2002;111:69-77.

24. Pánkowska E, Błazik M, Dziechciarz P, Szypowska A, Szajewska H. Continuous subcutaneous insulin infusion vs. multiple daily injections in children with type 1 diabetes: a systematic review and meta-analysis of randomized control trials. Pediatr Diabetes. 2009;10:52-8.

25. Barnard K, Thomas S, Royle P, Noyes K, Waugh N. Fear of hypoglycaemia in parents of young children with type 1 diabetes: a systematic review. BMC Pediatr. 2010;10:50.

26. McGarthy M. The everything parent's guide to children with juvenile diabetes: reassuring advice for managing symptoms and raising a healthy, happy child. New York: Adams Media and F+WPublications Company; 2007:33. 
Table 1. Characteristics of the Study Participants with Type 1 Diabetes Mellitus Treated with CSII and MDI (mean \pm SD) $(N=239)$

\begin{tabular}{|c|c|c|}
\hline & $\begin{array}{l}\text { Patients treated with } \\
\text { CSII therapy }\end{array}$ & $\begin{array}{l}\text { Patients treated with } \\
\text { MDI therapy }\end{array}$ \\
\hline$n$ & 104 & 135 \\
\hline Girls : boys ratio & 51:53 & $64: 71$ \\
\hline Age (year) & $13.29 \pm 2.85$ & $13.44 \pm 2.90$ \\
\hline Diabetes duration (year) & $6.03 \pm 2.52$ & $5.70 \pm 2.85$ \\
\hline $\mathrm{HbA}_{\mathrm{lc}}(\%)$ & $8.63 \pm 1.49$ & $8.75 \pm 1.60$ \\
\hline BMI z-score & $0.38 \pm 0.84$ & $0.36 \pm 0.79$ \\
\hline Insulin dose (units/kg/day) & $0.90 \pm 0.21$ & $0.93 \pm 0.19$ \\
\hline $\mathrm{VO}_{2 \max }$ of girls $(\mathrm{ml} / \mathrm{min} / \mathrm{kg})$ & $38.72 \pm 5.75(n=51)$ & $38.03 \pm 4.60(n=64)$ \\
\hline $\mathrm{VO}_{2 \max }$ of boys $(\mathrm{ml} / \mathrm{min} / \mathrm{kg})$ & $44.55 \pm 4.71(n=53)$ & $42.82 \pm 5.89(n=71)$ \\
\hline
\end{tabular}

CSII, continuous subcutaneous insulin infusion; MDI, multiple daily injections. 
Table 2. Total Score and Subscale Scores of Generic Core Scales and Subscale Scores of Diabetes Module for Child Self-Report and Parent Proxy-Report in Patients Treated with CSII and MDI

\begin{tabular}{|c|c|c|c|c|}
\hline & \multicolumn{2}{|c|}{ Child self-report } & \multicolumn{2}{|c|}{ Parent proxy-report } \\
\hline & $\begin{array}{l}\text { CSII therapy } \\
n=104\end{array}$ & $\begin{array}{c}\text { MDI therapy } \\
n=135\end{array}$ & $\begin{array}{c}\text { CSII therapy } \\
n=97\end{array}$ & $\begin{array}{c}\text { MDI therapy } \\
n=127\end{array}$ \\
\hline GCS total score & $82.1 \pm 9.2^{* * *}$ & $77.0 \pm 10.0$ & $79.3 \pm 9.0^{* * *}$ & $74.9 \pm 10.1$ \\
\hline Physical functioning & $84.6 \pm 9.8^{* *}$ & $80.8 \pm 11.1$ & $81.1 \pm 9.5^{* *}$ & $77.5 \pm 9.8$ \\
\hline Emotional functioning & $75.8 \pm 15.2^{* * * *}$ & $67.0 \pm 16.0$ & $72.8 \pm 15.0^{* * * *}$ & $63.8 \pm 14.9$ \\
\hline Social functioning & $90.6 \pm 13.6$ & $87.6 \pm 15.3$ & $88.3 \pm 13.4$ & $85.7 \pm 17.5$ \\
\hline $\begin{array}{l}\text { School functioning } \\
\text { DM subscale scores }\end{array}$ & $75.9 \pm 14.2^{* *}$ & $70.3 \pm 14.9$ & $74.1 \pm 14.2$ & $71.2 \pm 15.0$ \\
\hline Diabetes symptoms & $67.2 \pm 12.6^{* * *}$ & $61.4 \pm 13.5$ & $65.7 \pm 11.9^{* * *}$ & $60.0 \pm 12.5$ \\
\hline Treatment barriers & $72.5 \pm 19.8$ & $68.4 \pm 19.2$ & $68.7 \pm 19.4$ & $66.0 \pm 18.9$ \\
\hline Treatment adherence & $82.9 \pm 14.3$ & $81.8 \pm 14.1$ & $79.8 \pm 14.9$ & $77.8 \pm 13.4$ \\
\hline Worry & $71.4 \pm 20.7^{* * *}$ & $62.0 \pm 19.1$ & $66.9 \pm 20.9^{* *}$ & $57.1 \pm 21.7$ \\
\hline Communication & $77.2 \pm 21.2$ & $76.5 \pm 22.7$ & $74.8 \pm 20.9$ & $76.5 \pm 21.3$ \\
\hline
\end{tabular}

Table 3. Summary of Stepwise Multiple Regression Analysis for HRQoL

\begin{tabular}{lrrrr}
\hline Variables & B \pm SE & $\beta$ & $\dagger$ & $p$ \\
\hline (Constant) & $55.046 \pm 4.163$ & & 13.331 & .000 \\
VO $_{\text {mox }}$ & $0.650 \pm 0.098$ & 0.386 & 6.654 & .000 \\
CSII therapy CSII = = MDI = & $-4.410 \pm 1.160$ & -0.220 & -3.800 & .000
\end{tabular}

Note. Criterion variable is PedsQL Generic Core Scale, child self-report. $N=239$; $R=0.462, R^{2}=0.214$.

HRQLL, health-related quality of life; CSII, continuous subcutaneous insulin infusion; MDI, multiple daily injections. 